Genome

July 2015, Volume 58, Issue 7, Pages 333-348

http://dx.doi.org/10.1139/gen-2015-0014

http://archimer.ifremer.fr/doc/00278/38924/

(c) Published by NRC Research Press. Tous droits réservés 2014 -

Éditions Sciences Canada

\title{
Autotetraploid Pacific oysters (Crassostrea gigas) obtained using normal diploid eggs: induction and impact on cytogenetic stability
}

\author{
Benabdelmouna Abdellah ${ }^{1,{ }^{*}}$, Ledu Christophe ${ }^{1}$ \\ ${ }^{1}$ IFREMER, RBE-SG2M-LGPMM, Station Ronce les Bains, Avenue de Mus de loup, 17390-La \\ Tremblade, France \\ * Corresponding author :Abdellah Benabdelmouna, \\ email address : Abdellah.Benabdelmouna@ifremer.fr
}

\begin{abstract}
:
We describe two methods of producing viable and fertile autotetraploid Pacific oyster (Crassostrea gigas Thunberg) based on the use of normal-sized oocytes produced by normal diploid females. Our methods showed that the oocyte size is not a limiting factor for the success of the induction to autotetraploidy. These methods offer means of direct introgression of genetic progress from elite diploid lines to tetraploids used as broodstock, avoiding a triploid step with the risk of transferring undesirable traits from highly fecund triploids. High variability in the level of cytogenetic stability was found among the different tetraploid oysters tested showing that induction method has an important impact on the long-term cytogenetic stability of the tetraploids. It appears that induction method based on the use of triploid females induces a greater cytogenetic instability among tetraploids so obtained, and this compared to tetraploids originating from the two methods described in our present study. As the aneuploidies and reversions observed in tetraploids can have serious consequences for the sustainability of tetraploid broodstock itself as well as their triploid offspring, the two tetraploid induction methods described in the present work offer means to produce tetraploids with optimal cytogenetic, genetic and zootechnical performances
\end{abstract}

Keywords : Oyster, Tetraploid induction, Mosaicism, Aneuploidy, Cytogenetic stability 


\section{Résumé :}

Nous décrivons deux nouvelles méthodes de production d'huîtres du Pacific (Crassostrea gigas Thuneberg) autotétraploïdes basées sur l'utilisation d'ovocytes de taille normale issus de femelles diploïdes normales montrant ainsi que la taille des ovocytes n'est pas un facteur limitant pour la réussite de l'induction à la tétraploïdie. Ces méthodes permettent l'amélioration génétique des souches tétraploïdes en y transférant le progrès génétique réalisé dans le compartiment diploïde et ceci tout en évitant le risque de transférer les caractères indésirables potentiellement transmis par les femelles triploïdes hyper fécondes. Des différences très nettes concernant la stabilité cytogénétique ont été trouvées entre les différents groupes de tétraploïdes testés montrant que la méthode d'induction a un impact important sur la stabilité cytogénétique à long terme des huîtres tétraploïdes obtenues. II apparait que la méthode d'induction basée sur l'utilisation de femelles triploïdes induit une plus grande instabilité cytogénétique et cela comparativement aux méthodes d'induction que nous décrivons dans ce travail. Sachant que les aneuploïdies et les reversions observées chez les tétraploïdes posent de sérieuses menaces sur la pérennité des stocks de géniteurs tétraploïdes ainsi que sur la qualité de leurs descendants triploïdes, nos deux méthodes décrites dans ce travail offrent l'opportunité de produire de nouveaux stocks de tétraplö̈des avec des performances zootechniques, cytogénétiques et génétiques optimales.

Mots-clés : huître, tétraploïde induction, mosaicism, aneuploidie, stabilité cytogénétique 


\section{Introduction}

Most organisms are diploids, possessing a duplicated set of homologous chromosomes in their somatic cells. Polyploidy refers to the condition of a cell or organism that has extra complete sets of homologous chromosomes beyond the normal 2, with triploids having 3 and tetraploids having 4. Polyploidy is an important mechanism for genome evolution and speciation in both animals and plants (Stebbins 1971; Mable 2004; Hegarty and Hiscock 2007). Although lethal for mammals and birds, polyploidy can be induced in some commercially important aquaculture species of fish and shellfish, and spontaneous polyploids have been described in several phylogenetically distant orders, including both wild and farmed fish species (Gallardo et al. 1999; Alves et al., 2001; Arai 2001; Piferrer et al. 2009). Triploidy is now widely used in shellfish aquaculture, particularly in triploid Pacific oyster Crassostrea gigas aquaculture, which has developed into an industry in different countries around the world (Chew 1994; Rasmussen and Morrissey 2007). Triploidy can occur spontaneously at low but consistent frequencies in the Pacific oyster (Guo et al. 1992; Guo and Allen 1994), and this species is also one of the most successful models for ploidy manipulation in bivalves. Triploid Pacific oysters can be produced by artificial induction, which is usually performed by chemical treatment or physical stress such as heat shock or hydrostatic pressure applied on diploid $\mathrm{x}$ diploid crosses in order to prevent the release of the first or, more frequently, the second polar body in fertilized eggs (Allen and Downing 1986; Yamamoto et al. 1988; Gerard et al. 1999). However, none of these induction methods can guarantee $100 \%$ triploid production, and the chemical methods are expensive, potentially dangerous to the operator, and imply the use of very toxic chemicals on animals that are at the outset destined for human consumption (Guo and Allen 1994). At present, the crossing of gametes from induced tetraploids and normal diploids offers the most reliable way to obtain at reasonable cost $100 \%$ triploid production, with individuals that have high survival rates and are free of genetic defects from polar body inhibition (Guo and Allen 1994; Guo et al. 1996; Eudeline et al. 2000). This method of triploid production is clearly dependent on the successful development of viable and fertile tetraploids. However, despite strong interest and repeated attempts, the induction of tetraploids remains a serious challenge in shellfish genetics and breeding.

Theoretically, induction of tetraploidy on C. gigas can be achieved by several methods, including the suppression of the first mitosis, blocking of first polar body (PB1), gynogenesis, and blastomere fusion (Stephens and Downing 1988; Stephens 1989; Guo 1991; Guo et al. 1992; Guo et al. 1993; Guo et al. 1994). Although significant proportions of tetraploid embryos were detected following these methods, none survived beyond the spat stage. Different hypothesis were proposed to explain the lack of viability of induced tetraploid embryos, including the toxic effect of induction agents and the expression of lethal recessive alleles in tetraploids (recessive-lethal hypothesis). However, the main proposed explication for the lack of viability of induced tetraploid embryos was the "cell/cytoplasm deficiency" hypothesis (Guo, 1991; Guo and Allen 1994). According to this hypothesis, tetraploidy itself induces negative consequences in embryonic development. Compared to a diploid cell, a tetraploid cell is expected to contain twice as much nuclear material. Tetraploid cells will therefore be larger and require more cytoplasm than diploid cells. However, since the overall size of tetraploids remains similar to diploids, tetraploidy would lead to either a reduction in the number of cells or cells with insufficient amount of cytoplasm. Hence, this deficiency of 
cells or cytoplasm might prevent tetraploid embryos from developing normally. Guo (1991) proposed that the problem of cell-number deficiency in tetraploid embryos might be circumvented by an increase in egg volume. Although considered to be sterile, some triploid Pacific oysters produce substantial quantities of mature oocytes. Interestingly, eggs from triploids are significantly larger than normal eggs from diploid oysters, and this offered an alternative method for obtaining tetraploids. Consequently, tetraploids were successfully produced using eggs from triploids that were fertilized with haploid sperm taken from normal diploids, followed by chemical inhibition of PB1 (TrD+PB1, Guo and Allen 1994). This method was patented in the USA, with licenses for EU use (USA Patent \#5824841; 20/10/1998).

Another complementary method of tetraploid induction in C. gigas, adapted from the method of tetraploid induction established for the rainbow trout by Chourout et al. (1986), was proposed by McCombie et al. (2005a). This approach is closely dependent on the availability of an already established tetraploid broodstock and, to counter the negative effects of small diploid egg size, the authors exploited the natural variation in egg size between diploid females to select those oysters having larger eggs to serve as maternal parents in the induction cross. Thus, diploid females producing larger eggs were first identified; their eggs were then fertilized with diploid sperm from tetraploid males (obtained from TrD+PB1); and PB2 was then suppressed, leading to the production of a few tetraploid spat that survived up to six months, post-fertilization. As a matter of fact, tetraploid oysters obtained using these two methods could be considered as the progeny of a few highly fecund triploid females that were used as mothers (Guo and Allen 1994) and grandmothers (McCombie et al. 2005a). As a result, these tetraploid oysters may have inherited a genetic background responsible for high fecundity that could be transferred to their triploid offspring. In Pacific oyster aquaculture, high levels of gametogenesis in triploids is not a desirable characteristic, since triploid oysters are initially intended to be sold in summer, when diploids are fully ripe and have poor organoleptic quality. Consequently, the deliberate selection of triploid females with high fecundity to produce new tetraploid stocks may present a risk of producing subsequent triploids that show comparable or even higher fecundity than their triploid grandmothers. Additionally, studies on tetraploids obtained after TrD+PB1 induction and on their offspring showed a high incidence of genomic instability with poor cytogenetic quality, due to a high occurrence of aneuploidy and reversion (heteroploid mosaics) which appeared to increase with aging and environmental stress. Thus, with the aging of individuals, and across generations, it appears to be particularly difficult for these tetraploids to maintain their genetic stability as pure biotypes or broodstocks. Finally, although tetraploids faithfully make tetraploids when crossed with themselves and triploids when crossed with diploids, they also frequently produced offspring which were not of the desired ploidy class and/or which were of lower biological performances (Allen et al. 1996; Allen et al., 1999; Hand et al., 1999; McCombie et al. 2005b; Guo et al. 2009; Zhang et al. 2010a, Zhang et al. 2010b, Zhang et al. 2014a; Zhang et al. 2014b; Matt and Allen 2014). Thus, producing new tetraploids directly from diploids without the use of any genetic material from triploids would be a significant improvement.

In the present work, two tetraploid induction methods were established starting with normal diploid eggs. These two induction methods, established in 2006 and patented first in France in 2007, described production of viable and fertile tetraploid Pacific oysters after Diploid $\mathrm{x}$ Diploid (DD+PB1) crosses and called "direct method" (Benabdelmouna and Ledu 2007. FR patent \#2913982-A1), and after Diploid x Tetraploid (DT+PB2) crosses, designated in the present work as “indirect method" (Benabdelmouna et al. 2007. FR patent \#2913983-A1). These two induction methods allowed us to constitute different broodstocks of tetraploid 
oysters without any triploid parents in their lineage. These new tetraploid oysters were compared to tetraploid oysters from the broodstock initially produced in France in 1997 after triploid x diploid crosses (TrD+PB1) according to the method of Guo and Allen (1994 and USA Patent \#5824841; 1998). To evaluate the effect of induction method, DD+PB1 versus TrD+PB1, on the biological performances of tetraploid oysters, and in order to avoid confounding the effect of the induction method with the effect of the genetic background of founders, we produced two additional tetraploid broodstocks started from genitors having the same genetic background. Thus, tetraploid oysters were obtained in 2012 following PB1 inhibition after diploid x diploid crosses (Benabdelmouna and Ledu 2007) and triploid x diploid crosses (Go and Allen 1994), thereby permitting the assessment of whether the induction method can influence cytogenetic and overall biological quality of induced tetraploids, and potentially the quality of all-triploid spat produced by commercial hatcheries.

\section{Materials and methods - Parents and gametes}

In 2006, unselected and unrelated diploid and tetraploid C. gigas to serve as genitors were conditioned to sexual maturation for two months, starting in January at the Ifremer experimental hatchery in La Tremblade (France). Diploid C. gigas oysters were three year old adult individuals bought from local oyster farmers working exclusively with wild-caught spat. These diploid C. gigas oysters were conditioned to maturation in an open circulating system at $20^{\circ} \mathrm{C}$. Tetraploid oysters used in this work were two years old and were conditioned to maturation in the same conditions as the diploids, but in a quarantine area equipped with water treatment systems using ozone to prevent dissemination of gametes or larvae. In this work, tetraploid oysters were used as males, and samples were from the same tetraploid broodstock used for the mass production of triploids by the French commercial hatcheries. This tetraploid broodstock was initially produced in 1997 in the Ifremer experimental hatchery using triploid x diploid cross according to the method developed by Guo and Allen (1994). This tetraploid broodstock was later maintained by successive mass crossing between tetraploid males and females to produce successive generations of tetraploid oysters.

In 2010, oysters from the same genetic background were used in two induction experiments to produce two different tetraploid oyster batches by means of the two patented methods of tetraploid induction currently in use in the world for commercial all-triploid productions (USA Patent \#5824841; 20/10/1998 and FR patent \#2913982-A1; 23/03/2007). Thus, the eggs from 20 diploid females were collected and divided into two pools. Each pool was then fertilized by the same pool of spermatozoa from 10 diploid males. One of the two pools was then reared to produce diploid offspring, while the second pool was used for the production of triploids that were chemically induced using cytochalasin B (CB, Sigma C6762) to block the second polar body (PB2), according to the protocol of Gérard et al. (1999). In 2012, the two year old diploid and triploid oysters thus obtained were conditioned to gametogenesis and used to produce tetraploid offspring after PB1 inhibition during diploid $\mathrm{x}$ diploid crosses (Benabdelmouna and Ledu 2007, FR patent \#2913982-A1; 23/03/2007) or triploid x diploid crosses (Go and Allen 1994, USA Patent \#5824841; 20/10/1998).

\section{Gametes handling, fertilization and Cytochalasin B treatments}

For all of the experiments performed in 2006 and 2012, the crossing design included one diploid control progeny and two induction crosses. In 2006, 140 million oocytes were collected from six diploid females. Unfertilized eggs from Pacific oysters are pear-shaped, so 
their diameter was estimated immediately after fertilization (3-5 min PF), when the eggs became spherical. Samples of oocytes from each diploid female were collected and fertilized by spertamotozoa from diploid males. 20 eggs were then measured for each of the six diploid females used in this work. No significant variation in egg size within or among females was found, and the mean egg diameter was $49-51 \mu \mathrm{m}$.

In 2006, the diploid and tetraploid genitors used for the induction experiments were taken from unselected and unrelated stocks.

- In the first induction experiment, using the DT+PB2 or "indirect method", 15 million oocytes from six diploid females (D) were fertilized with spermatozoa from four tetraploid males (T). At $20 \mathrm{~min} \mathrm{PF}$, oyster embryos were incubated with CB at $0.5 \mathrm{mg} / \mathrm{l}$ for 15 min in order to suppress expulsion of PB2. This induction method differed from the method developed by McCombie et al. (2005), particularly in that the diploid females were not subjected to any intentional selection, notably for the large size of their eggs.

- In the second induction experiment, using the DD+PB1 or "direct method", 15 million oocytes from the same six diploid females were fertilized with spermatozoa from four unselected diploid males. At $10 \mathrm{~min}$ PF, oyster embryos were incubated with CB at $0.5 \mathrm{mg} / \mathrm{l}$ for 15 min in order to suppress expulsion of PB1.

In 2012, two induction experiments were conducted using genitors from the same genetic background. A first tetraploid batch was produced using our DD+PB1 method (Benabdelmouna and Ledu 2007), and a second tetraploid batch was produced according to the TrD+PB1 method established by Guo and Allen (1994). In this last induction group, 10 million oocytes from six triploid females (Tr) were fertilized with spermatozoa from four diploid (D) males. At 5 min PF, oyster embryos were incubated with CB at $0.5 \mathrm{mg} / \mathrm{l}$ for 15 min in order to suppress expulsion of PB1.

After each treatment period, the CB was thoroughly washed off the embryos by filtering the samples on a $10 \mu \mathrm{m}$ sieve, and the embryos were rinsed in DMSO $(1 \mathrm{ml} / \mathrm{l})$ in FSW for at least 15 min.

\section{Larval and spat culture}

At $50 \mathrm{~min} \mathrm{PF}$, control and treated larvae were transferred to $150 \mathrm{l}$ volume fiberglass tanks of FSW at $22-24^{\circ} \mathrm{C}$ and grown for $24 \mathrm{~h}$ at a density of 100 larvae/ml. At Day $1 \mathrm{PF}$, the larvae were collected by sieving on a $45 \mu \mathrm{m}$ nylon mesh, and the percentage of abnormal larvae was recorded for each batch. At that stage, each larva that was not D-shaped was considered abnormal. The water in the tanks was changed every two days. The larvae were cultured under standard rearing conditions. At each water change, the larvae were subdivided into different size classes. The DNA Ploidy level of each size class was then verified by Flow CytoMetry (FCM) to identify the ones with the highest percentage of tetraploid larvae. Cultures were conducted until metamorphosis and settlement. As for larvae, spat were periodically sorted out by size and different size classes were constituted. The DNA Ploidy level of each size class was then verified by FCM to determine the one with the highest percentage of tetraploid oysters. Afterward, only those size classes having the highest percentage of tetraploidy were maintained and used for nondestructive identification of tetraploid oysters. During the larval and spat culture, all seawater discarded after water change was treated with ozone to prevent the escape of polyploids or their gametes into the open environment. 


\section{DNA Ploidy determination}

DNA ploidy levels were determined by FCM. At 24 h PF, FCM analysis was used to control initial induction success. Subsequently, FCM was used to monitor the constitution of tetraploid-rich batches during larvae and spat culture. For each FCM analysis, at least 2000 sample nuclei were analyzed and an internal standard (TRBC, Coulter DNA Reference Calibrator, 629972) was systematically analyzed together with sample nuclei. The DNA ploidy level was controlled at different stages of the oyster life cycle, including genitors, male gametes, larvae and spat. For adult oysters, the DNA ploidy level was individually confirmed using both somatic tissues (gills) and spermatozoa. For larvae, FCM analyses were performed at each water change on pools of about 100 individuals that were crushed together using piston pellets and hence concerned populations of larvae with mixed ploidy levels. FCM results of these larvae should be considered as an indication of the global ploidy level of the analyzed sample. More precise FCM analysis were performed for spat that were individually analyzed and only histograms with internal standard cells showing a peak with a standard coefficient of variation (CV\%) below 3\% were considered for subsequent analyses. DNA ploidy level determination for small spat (1-5 mm) was destructive and determined using the whole body. For larger spat (above $10 \mathrm{~mm}$ ), DNA ploidy level determination was nondestructive and performed by using small pieces $\left(1 \mathrm{~mm}^{2}\right)$ of gill tissue collected from $\mathrm{MgCl}_{2}$-anesthetized juveniles. Peak positions for sample and internal standard were calculated using PARTEC PAS II software package, and the ratio between respective peak positions of sample and internal standard nuclei is characteristic of sample genome size and DNA ploidy levels. In our laboratory conditions, this ratio equals $0.42 \pm 0.02$ for diploids, $0.62 \pm 0.02$ for triploids and $0.82 \pm 0.02$ for tetraploids.

\section{Chromosome number verification}

The chromosome numbers of tetraploid oysters identified after FCM analyses were also verified using karyology. To block the mitosis in metaphase, samples of 6 tetraploid oysters were incubated overnight in seawater containing $0.005 \%$ colchicine. Oysters were then dissected, and their gill tissues were treated for $40 \mathrm{~min}$ in $0.9 \%$ sodium citrate and fixed in a freshly prepared mixture of absolute ethanol-acetic acid (3:1). Slides were then made following the air-drying technique, and the chromosomes were counterstained with DAPI. The Pacific oyster has a diploid number of 20 chromosomes (Ahmed 1973). Only oysters with 40 chromosomes were considered to be tetraploid. For each individual analysis, microscopic observations used two slides with 8 to 10 well spread metaphases with no obvious chromosome loss or gain (over spreading or clumping). A chromosome number was accepted when all high-quality metaphases from the same oyster showed the same chromosome number. Digital images of chromosomes were captured using a 100x objective coupled to a Zeiss Axioplan 2 Imaging microscope equipped with the appropriate filter set for DAPI. Digitized images (gray scale) were prepared for printing in Axiovision software (Zeiss).

\section{Genome stability of induced tetraploids}

To compare the cytogenetic stability of the different tetraploid broodstocks produced in 2006 and 2012, karyological and FCM analyses were performed on two year old tetraploid oysters. Nondestructive FCM analyses were first used to constitute three batches of 200 tetraploid oysters each in 2006, and two subsequent batches in 2012. The different tetraploid batches 
were then reared under the same zootechnical conditions and protected from open field conditions in our quarantine facility equipped with UV sterilized and $1 \mu \mathrm{m}$-filtered sea water which enabled us to maintain our studied oyster populations without any mortality event. In order to evaluate their genome stability, nondestructive FCM analyses were performed again on all oysters at the end of their second year of rearing. Selected tetraploid and heteroploid mosaic oysters were also verified by karyological studies using chromosome counts prepared from gill tissues as described earlier. This allowed final calculation of the percentage of tetraploid versus non-tetraploid oysters (heteroploid mosaics) for each batch.

\section{Results}

The percentage of fertilized eggs measured at 2 hour PF was very high (90-95 \%) and was not drastically different according to ploidy of spermatozoa (haploid versus diploid) or between treated and control batches. However, at 24 hours PF, survival of developing eggs to D-stage was highly variable among batches. D-stage larvae were collected by sieving on a $45 \mu \mathrm{m}$ nylon mesh placed above a $20 \mu \mathrm{m}$ nylon mesh intended to collect unfertilized eggs and abnormal larvae. At $24 \mathrm{~h} \mathrm{PF}$, CB treated batches showed the lowest percentage of survival: 4-6 \% survival of D-stage larvae from DT+PB2 cross, and 16-20 \% survival of D-stage larvae from DD+PB1 cross. In contrast, the diploid (DD) control batch showed the highest percentage of D-stage larvae survival: 65\% (Table 1). In treated groups, abnormal larvae collected by the $20 \mu \mathrm{m}$ nylon mesh were small trochophores covered with cilia all over their spherical bodies. Placed in separate tanks in the same culture conditions, these abnormal larvae never did reach D-stage and gradually died during the first week post-fertilization.

FCM measurement of the DNA ploidy level of larvae at $24 \mathrm{~h}$ PF showed different profiles (Fig. 1). As expected, larvae from the control group were all diploids, as evidenced by the single diploid peak on Day 1 (Fig. 1A). Larvae in the treated groups had different patterns, with peaks at 2n, 3n and 4n. The "indirect method" (DT+PB2) produced broad, overlapping and difficult to separate peaks, indicating that, in addition to tetraploids, diploid, triploid and aneuploid/dying larvae were also present in this group (Fig. 1B). The "direct method" (DD+PB1) produced populations of larvae composed of $17 \%$ diploids, $38 \%$ triploids and $45 \%$ tetraploids (Fig. 1C).

For each induction trial, larval rearing continued until settlement. At Day 18, eyed and pediveliger larvae appeared and started metamorphosis. In the control group, as expected, all pediveliger larvae were in the diploid range (Figs. 2-3 A). FCM analysis of pediveliger larvae representing $40 \%$ of total larvae from the "indirect method" showed that larvae in the tetraploid range constituted almost half of the population which had been put to settle while triploids and diploids represented $47 \%$ and 5\%, respectively (Fig. 2 B). Otherwise, FCM analysis of larvae from the smaller size class $(180 \mu \mathrm{m}, 60 \%$ of total larvae) of this "indirect method" showed that this size class was essentially constituted (70\%) of larvae with ploidy levels varying from triploids to tetraploids (Fig. 2 C). Interestingly, no tetraploid peak was detected in the first settlement cohort of larvae produced by the "direct method". FCM patterns of pediveliger larvae representing $50 \%$ of total larvae and produced by this method showed only triploid and diploid peaks, at $70 \%$ and 30\% respectively (Fig. 3 B). FCM analysis of larvae detected nuclei in the tetraploid range only in the smaller size classes. Thus in the "direct method", $20 \%$ of larvae were in the tetraploid range in the medium $(180 \mu \mathrm{m}$, $20 \%$ of total larvae) size class, while $40 \%$ of larvae were in this tetraploid range in the smallest (150 $\mu \mathrm{m}, 30 \%$ of the total larvae) size class (Figs. 3 C-D). Larval cultures continued until all larvae from successive small size classes reached pediveliger stage (above $220 \mu \mathrm{m}$ ) and were put to settle. As larvae from the "direct method" exhibited the slowest growth rate, 
settlement was accomplished by Day 23 PF for larvae from the "indirect method", and by Day 29 PF for larvae from the "direct method".

In 2012, starting from genitors with the same genetic background, tetraploid larvae and spat were obtained using DD+PB1 (Benabdelmouna and Ledu 2007) and TrD+PB1 (Guo and Allen 1994) methods. Initial tetraploidy induction and larval growth rate were higher for larvae in the TrD+PB1 induction method. Additionally, with Tetraploid larvae were identified in the large size class representing more than $60 \%$ of total larvae and pediveliger larvae first appeared on Day 16 for this induction (table 1). At the same time in the DD+PB1 induction, tetraploid larvae were not pediveliger and were identified in the medium and small size classes $(150-180 \mu \mathrm{m})$. Larval cultures continued until all viable tetraploid larvae from successive small size classes reached pediveliger stage and were put to settle. This was accomplished by Day 20 PF for larvae from the TrD+PB1 method and only by Day 30 PF for larvae from the DD+PB1 method.

There was no visible post-settlement mortality in 2006 and 2012 experiments. Depending on growth, spat were periodically sorted out by size into different classes, in the same way as for larval culture. At two months PF (one month post-settlement), destructive FCM analyses were performed to verify the presence of viable tetraploid spat. Starting from six months PF, nondestructive FCM analyses were conducted, leading to the constitution of two tetraploid Pacific oyster batches with several hundred individuals each (Fig. 4). In order to verify the chromosome counts for oysters identified as tetraploid by FCM analyses, metaphase preparations were prepared from gill tissues collected from samples of selected juveniles. According to our karyological analyses, all oysters identified as tetraploid by FCM - i.e. oysters with a ratio of $0.82 \pm 0.02$ - appeared to be eutetraploid, with 40 chromosomes (Fig. 5.).

The observed low larval viability and growth rate for larvae from DD+PB1 inductions was no longer evident at spat stage. Tetraploid spat from these inductions were fully viable and showed normal growth and evolution. This was subsequently evidenced during the rearing process, when individually sorted tetraploid spat were cultivated in pure tetraploid batches. In this case, these tetraploid oysters showed a similar, and even higher, growth rate than their counterpart tetraploid oysters obtained using TrD+PB1 or DT+PB2 inductions (not showed). Finally, induced tetraploid oysters survived until adult age and were able to reach normal sexual maturation. All of these tetraploid oysters produced in 2006 and 2012 appeared to be fully fertile and produced normal amounts of functional gametes. Males and females were effectively obtained for each tetraploid group and were used to produce new generations of tetraploid offspring. Additionally, after crossing with diploid females, males from each tetraploid group were also successfully used to produce all-triploid spat.

\section{Cytogenetic stability of induced tetraploids}

Starting with tetraploid oysters produced in 2006 and 2012, nondestructive FCM analyses were used to constitute different batches of 200 tetraploid oysters each. Two years later, nondestructive FCM analyses were performed again for each batch, on all of the 200 oysters initially identified as tetraploids. Contrasting results were obtained in terms of cytogenetic stability for the different batches (Table 2). Kruskal-Wallis non parametric test with multiple pair comparison of Dunn showed significant differences between the three induction $(\mathrm{K}=35.536, \mathrm{df}=2, \mathrm{p}<0.0001)$. For the tetraploid oysters induced in 2006, tetraploids originating from the TrD+PB1 experiment showed low cytogenetic stability with only $55 \%$ of the oysters were still eutetraploids, while $45 \%$ had reverted and were identified as mosaics. In contrast, $75 \%$ of the oysters originating from the TD+PB2 experiment were still tetraploids, 
while only $25 \%$ were identified as mosaics. In contrast, the highest cytogenetic stability was exhibited by the tetraploids originating from the DD+PB1 experiment with $93 \%$ of the oysters were detected as still being eutetraploid, while only $7 \%$ had reverted to a heteroploid mosaic status.

Comparable results with significant difference were found for the oysters from the same genetic background and induced to tetraploidy in 2012 (bilateral test of Mann-Whitney, $\mathrm{U}=2750, \mathrm{p}<0.0001$ ). In this case, cytogenetic stability of tetraploids originating from the TrD+PB1 experiment was also low: only $50 \%$ of the oysters were still tetraploid, while $50 \%$ were not tetraploid and had reverted to mosaics. Alternatively, 95\% of the oysters originating from the DD+PB1 experiment (direct induction) were detected as tetraploid, with only 10 oysters (5\%) having reverted to a heteroploid mosaic status.

Eutetraploid individuals showed characteristic flow cytometric histograms with one peak and a ratio of $0.82 \pm 0.02$ (Fig. 6-A). Chromosome counts for oysters identified as eutetraploid by FCM analyses only showed metaphase plates with 40 chromosomes (fig. 7-I). Cytometric and karyological patterns obtained for heteroploid mosaics were more complex. In addition to tetraploid cells with a normal peak and chromosome count (i.e. peak with a ratio of 0.82 \pm 0.02 and metaphase plates with 40 chromosomes), heteroploid mosaics showed varying proportions of mainly aneuploid cells, represented as broad, continuous and variable cytometric peaks (Fig. 6 B-D), and metaphase plates corresponding with flow-cytometric analysis showing different chromosome constitution, including hypotetraploids, hypertriploids and hyperdiploids (Fig. 7 II-IV).

\section{Discussion}

In France, Pacific oyster production is based on two types of spat, wild-caught and hatcheryproduced, with different percentages for each type each year. Hatchery-produced spat is increasing regularly each year, with most of the production being triploids. During the last decades, the amount of hatchery-produced spat worldwide has increased steadily each year, and this great development has been accompanied by the initiation of many selective breeding programs (Sheridan 1997; Nell et al. 2000; Ward et al. 2000; Langdon et al. 2003; King et al. 2004). Although the most significant genetic improvement for the production of Pacific oysters has been obtained through the breeding of triploids, these programs have only been initiated on diploid stocks, as the selective breeding of tetraploids is considered to be much more complex than that of diploids. Additionally, the selection of tetraploids is also restricted by the strict quarantine conditions applied for their culture. Consequently, in order to provide commercial hatcheries with the best breeders for the production of genetically improved triploids, the need to develop tetraploid lines from the selected diploid broodstocks currently available, or in progress, is of decisive importance. In this regard, our two methods of tetraploid induction described in this work appear to be effective means for generating tetraploids de novo - either from improved elite diploid strains (direct method) or, alternatively, by integrating new genetic material from these elite diploid strains into existing tetraploid broodstock families (indirect method). Thus, starting in 2006, we used a two-step strategy that combined both "direct" and "indirect" induction methods to genetically improve our C. gigas tetraploid lines used as broodstock. In this strategy, the first step consisted of using the "direct" induction method to generate tetraploids de novo from elite diploid lines obtained through mass and/or family based selection. The second step consisted of using the "indirect" induction method to extend the genetic basis of the tetraploids so obtained, by using additional germplasm from the same or, alternatively, an unrelated elite diploid line used as female in DT+PB2 diploid crosses. For example, in 2010, starting with selected diploid 
oysters resistant to the Ostreid Herpes Virus-1 (OsHV-1) associated with recurrent massive mortality primarily affecting juveniles of $C$. gigas (Dégremont 2011), the "direct" induction method was used to produce an improved tetraploid strain (Tetra R). After that, crossing both improved tetraploid males and diploid females opened the way to mass production of genetically improved all-triploids (Triplo R). This approach was recently implemented using both diploid and tetraploid resistant genitor families, and all-triploid resistant oysters have been in production since 2012 in France under the name of “oyster rescue plan”.

In our study, viable and fertile tetraploid Pacific oysters were obtained after direct (DD+PB1) and indirect (DT+PB2) tetraploid induction methods starting with normal diploid eggs. Diploid eggs used in our study were very comparable in size (50 $\mu \mathrm{m}$ versus $49.6 \mu \mathrm{m}$ ) to eggs used in their study by Guo and Allen (1994) but were significantly smaller (50 $\mu \mathrm{m}$ versus 60 $\mu \mathrm{m}$ ) than those used by McCombie et al. (2005a). Our study - and many others inductions we realized latter -clearly showed that tetraploids can be obtained from diploid eggs of normal size which are capable of carrying a tetraploid genome and successfully differentiating into viable animals. We therefore do not support the cell-number deficiency hypothesis (Guo and Allen 1994) and have shown that tetraploid induction can be successfully achieved using diploid eggs of normal size and is not restricted to diploid females with the largest egg size (McCombie et al. 2005a). One possible explanation for the success of tetraploid induction obtained using our methods could be due to their relatively lower toxicity, comparatively to other previously tested procedures. To achieve this, both treatment duration and CB concentration were lowered in our induction methods - from $20 \mathrm{~min}$ to $15 \mathrm{~min}$ for the treatment duration, and only $0.5 \mathrm{mg} / \mathrm{ml}$ for CB concentration instead of the routinely used 1 mg/l CB treatments (Downing and Allen 1987; Guo et al. 1992; Gerard et al. 1994). However, even though CB is known to be very toxic and deleterious to survival of larvae, CB treatment per se is only part of the explanation and may not be the fundamental cause of reduced survival of tetraploid larvae. Indeed, diploid and triploid larvae are viable in numerous other studies after similar CB treatments (Downing and Allen 1987; Guo and Allen 1992; Gerard et al. 1994). In addition to this explanation, we hypothesized that reduced survival of tetraploids was directly linked to tetraploidy itself inducing lower global fitness for tetraploids, compared to diploids and triploids. Numerous attempts have shown that tetraploids have a limited viability in most bivalve species studied, and even for the tetraploids that passed D-stage, their growth was severely retarded compared to diploids, so that very few, if any, tetraploid embryos survive beyond the larval stage. This negative effect of tetraploidy is probably linked to an imbalance in gene expression, which in turn affects larval development (Diter and Dufy1990; Guo et al. 1993; Guo et al. 1994; Que et al. 1997; Yang et al. 2000; Yang and Guo 2004; McCombie et al. 2005a; Yang and Guo 2006). Additionally, blocking PB1 is known to cause abnormalities in chromosome segregation, such as tripolar segregation and uneven distribution of chromosomes, leading to massive aneuploidy and reduced viability (Guo et al. 1992). However, in our method, following initial induction of high percentages of tetraploid larvae, we assumed that a significant proportion of these tetraploid larvae were fully viable and could be conducted to metamorphosis and beyond if favorable hatching conditions were provided.

Blocking the release of PB1 in C. gigas and other mollusks frequently resulted in triploids, aneuploids and also tetraploids suggesting that this phenomenon is linked to complicated chromosome segregation during the meiosis (Guo et al. 1992). Tetraploid induction after DD+PB1 was explained by These authors who showed that blocking PB1 dramatically changed chromosome segregation in meiosis II leading to the release of one set of chromatids as PB2 from an "unmixed tripolar" or a "separated bipolar" segregation which formed noticeable amounts of tetraploid larvae along with diploid, triploid and aneuploidy larvae. We assumed that tetraploid larvae produced during this work were originated from the same 
mechanism. Consequently, these tetraploids should normally have a reduced level of heterozygosity, compared to those produced by blocking PB1 after triploid x diploid crosses (TrD+PB1) or those produced by blocking PB2 after diploid $x$ tetraploid crosses (DT+PB2). This probably explains the observed differences of larval viability and growth rate in the different induction methods. Tetraploid larvae obtained after TrD+PB1 and DT+PB2 inductions showed higher viability and faster growth compared to tetraploid larvae from $\mathrm{DD}+\mathrm{PB} 1$ induction. Although a reduction in the level of heterozygosity is probably more problematic in the larval stage than after, it could also be assumed that the viable tetraploid larvae and spats obtained using the DD+PB1 method were a direct result of the drastic selection made during the larval stage, when all unviable larvae were eliminated. Tetraploid larvae that survived following this selection were fully viable and showed normal growth and evolution. This was subsequently clearly evidenced during the rearing process, when individually sorted tetraploid spat were cultivated in pure tetraploid batches.

In this study, important differences in term of cytogenetic stability were found in the three types of tetraploid oysters groups that were studied for this work. In our first experiment using C. gigas tetraploids originating from different genetic backgrounds, our results show the greatest cytogenetic stability for tetraploids inducted according to the direct method (DD+PB1). To avoid confounding the effect of the tetraploid induction method with that of the oysters' genetic background, we realised a second comparative study of cytogenetic stability using oysters originating from the same genetic background. The comparison of the cytogenetic stability of the various tetraploid stocks confirmed our earlier results, notably the very significant difference between tetraploids originating from the direct method (DD+PB1) and the tetraploids originating from triploid oocytes (TrD+PB1). Our results concerning the low cytogenetic stability of tetraploids originating from the TrD+PB1 method fully agree with the recently published results concerning tetraploids from C. gigas (Zhang et al. 2014a,b) and C. virginica (Matt and Allen 2014), which were inducted using the same method. In these studies, the majority of oysters initially identified as being tetraploids are no longer so during the course of their development, with the emergence of a high proportion of mosaic and aneuploid oysters. These results, obtained with different and unrelated stocks of $C$. gigas and $C$. virginica, tend to show that the tetraploid induction method has an important impact on the long-term cytogenetic stability of the tetraploids so obtained. It notably appears very plausible that the induction method based on the use of triploid females (TrD+PB1) induces a greater cytogenetic instability among tetraploids so obtained, and this compared to tetraploids originating from the two methods described in our present study. The principal difference between these various methods is that the TrD+PB1 method is based on the manipulation of the meiosis of oocytes produced by the triploid females, notably by blocking expulsion of the first polar body, while the two methods described in our work are based on the manipulation of the meiosis of oocytes produced by diploid females, with blocking of the expulsion of the first or second polar body. With diploids, manipulation of the ploidy via expulsion of the first polar body is known to promote anomalies in the segregation of chromosomes, notably with uneven distributions of chromosomes that frequently lead to massive aneuploidy (Guo et al. 1992). In view of the present study's results concerning cytogenetic stability among the various tetraploids that were studied, we propose that it is probable that the manipulation of meiosis, particularly via the blocking of the expulsion of the first polar body, has a much higher impact on triploid oocytes than on diploid oocytes, due to the greater numbers of chromosomes that are concerned by the meiotic segregation in triploid oocytes. The blocking of the expulsion of the first polar body during a triploid-diploid cross (TrD+PB1) very likely leads to the production of offspring that are initially considered to be tetraploid but which rapidly lose this status, either due to an initial aneuploidy that goes undetected by current methods, or to a genetic predisposition that is transmitted by the parents. Guo and Allen Jr. 
(1994) have shown that, in an oyster population that has been initially identified by flow cytometry as being tetraploid, a significant proportion (17\%) are in reality aneuploid (hypo and hyper-tetraploid). In C. gigas, the aneuploids and mosaics are viable (Guo and Allen Jr. 1994; Zouros et al. 1996; Wang et al. 1999; Gong et al. 2004; Zhang et al. 2010a,b), so it is plausible that these hyper-hypo tetraploids produce aneuploid gametes and then new offspring that are themselves in significant part aneuploids. However, the very high incidence of mosaics and aneuploids observed in this study -particularly among oysters originating from the method based on the use of triploid oocytes - cannot be explained only by the presence of aneuploid gametes. Thus, even if reversion may be considered as being present in all the various types of tetraploid oysters studied in this work, the notable differences in cytogenetic stability among the different tetraploids studied strongly suggest that there is an additional cause originating from a genetic predisposition for reversion that is in all likelihood transmitted via maternal triploid heredity, and this especially since triploidy among C. gigas as well other oyster species is also frequently accompanied by reversions. This predisposition for reversion linked to maternal triploid heredity is a plausible explanation for the higher level of cytogenetic instability observed for corresponding tetraploid oysters. Hence, when this genetic predisposition for reversion is directly and fully transmitted by triploid oocytes (TrD+PB1 method), the tetraploid oysters so obtained present poor cytogenetic quality, with a majority of oysters (50-55\%) rapidly losing their tetraploid status to become mosaics/aneuploids. Alternatively, when this genetic predisposition for reversion is only partially transmitted - as is the case following the DT+PB2 method, using tetraploid males that are themselves originating from triploid oocytes - the new tetraploids so obtained present better cytogenetic quality than their predecessors, with nevertheless a significant percentage of oysters (25\%) losing their tetraploid status to become mosaics/aneuploids. Finally, when the tetraploids are obtained directly from diploids and without any genetic background from triploid females in their pedigree (DD+PB1 method), the tetraploids' cytogenetic stability is highest, with only $5 \%$ of oysters losing their cytogenetic status to become mosaics/aneuploids.

The different ploidy levels described in this study were established using flow cytometry, as well as chromosome counts on metaphase plates obtained from gill cells. Our flow cytometry results had a strong correlation with the chromosome counts. Thus, the animals identified by flow cytometry as being eutetraploid were cytologically confirmed as having 40 chromosomes. Likewise, the animals identified as having cytometric peaks that corresponded to aneuploid nuclei presented aneuploid metaphase plates under cytological analysis. We attribute the strength of our analyses notably to the systematic use of an internal biological standard. It is indeed important to note that the various similar studies of this sort have all been done without an internal standard, or at best using sperm originating from a wild diploid male of the same species as an internal standard. However, C. gigas, is known to show frequent and significant variations in genome size within a given population, thus making cytometric measurements risky, with ploidy levels that cannot be determined with the necessary precision. This notably explains the fact that, in these studies, many oysters identified by flow cytometry as being "tetraploids" were discovered to be in reality aneuploids. In agreement with the results of Zhang et al. (2014a), and in disagreement with those published by Matt and Allen (2014), our results show that the individual mosaics, so identified in our work by the two detection methods, all presented gills with different percentages of eutetraploid cells (with 40 chromosomes) and cells that were most often aneuploid (hypo-tetraploid, hypo/hyper-triploid, hyper-diploid). The simultaneous presence of both eutetraploid cells and aneuploid cells does not fit with an explanation of the reversion being due to the total loss of one or several sets of chromosomes, but rather reinforces the idea that the reversion is a gradual phenomenon in which the shift from tetraploidy to a more 
stable state occurs via a progressive loss of chromosomes during the successive mitotic divisions. Following observations of triploids and tetraploids C. gigas and C. ariakensis, Zhang et al. (2014a) proposed a mechanism for this reversion that calls for a progressive loss of chromosomes following the phenomenon of "chromosome clumping" that occurs during mitotic divisions. Although we were not able to examine this particular aspect in our study, we too think that the reversion observed in our work could be explained by this same phenomenon.

The cytogenetic stability of tetraploid stocks is not only of great scientific interest. It represents also a serious commercial challenge on account of tetraploids being used as genitors for the commercial production of all-triploids (Zhang et al. 2010a,b; Matt and Allen 2014). The aneuploidies and reversions observed in tetraploids can thus have serious consequences for both the sustainability of tetraploid broodstock itself as well as their triploid offspring, whose cytogenetic quality, and hence zootechnical performance, can no longer be guaranteed. In this study, the two tetraploid induction methods as well as the method of ploidy levels characterization using flow cytometry that we describe allowed us to produce tetraploids whose cytogenetic stability and zootechnical performances were optimal. The methods described also allow for the production of tetraploids having a broader genetic base, and also benefitting directly from the genetic progress made with the diploids. The next steps of our work will focus especially on the comparative study of triploids originating from these various tetraploids. Different batches of triploids - produced with the same genetic background, or not - will be studied for their overall biological performance, notably in terms of cytogenetic stability, survival, growth, and investment in gametogenesis.

\section{Acknowledgements}

We thank the hatchery, nursery and genetic teams of the Laboratory of Genetics and Pathology, IFREMER La Tremblade and IFREMER Bouin for their assistance in oyster production. 


\section{References}

Ahmed, M. 1973. Cytogenetics of oysters. Cytologia, 38: 337-347.

Allen Jr., S.K., Howe, A., Gallivan, T., Guo, X., and DeBrosse, G. 1999. Genotype and environmental variation in reversion of triploid Crassostrea gigas to the heteroploid mosaic state. J. Shellfish Res. 18: 293 (abstract).

Allen, S.K. Jr, Guo, X., Burreson, G. and Mann, R. 1996. Heteroploid mosaics and reversion among triploid oysters, Crassostrea gigas: fact or artifact. J. Shellfish Res. 15: 514-522.

Allen, S.K. Jr., and Downing, S.L. 1986. Performance of triploid Pacific oysters, Crassostrea gigas (Thunberg). I. Survival, growth, glycogen content, and sexual maturation in yearlings. J. Exp. Mar.Biol. Ecol. 102: 197-208.

Alves, M.J., Coelho, M.M., and Collares-Pereira, M.J. 2001. Evolution in action through hybridisation and polyploidy in an Iberian freshwater fish: a genetic review. Genetica, 111: 375-385.

Arai, K. 2001. Genetic improvement of aquaculture finfish species by chromosome manipulation techniques in Japan. Aquaculture, 197: 205-228.

Benabdelmouna, A., and Ledu, C. 2007. Obtention de mollusques bivalves tétraploïdes à partir de géniteurs diploïdes. FR patent \#2913982-A1

Benabdelmouna, A., Ledu, C., and Gerard, A. 2007. Obtention de mollusques bivalves tétraploïdes à partir du croisement de femelles diploïdes et de mâles tétraploïdes. FR patent \#2913983-A1.

Chew, K.K. 1994. Tetraploid Pacific oyster offer promise to future production of triploids. Aquaculture Magazine, 20: 669-674.

Chourrout, D; Chevassus, B; Kreig, R; Happe, A; Burger, G; Renard, P. 1986. Production of second generation triploid and tetraploid rainbow trout by mating tetraploid males and diploid females: potential of tetraploid fish. Theor. Appl. Genet. 72: 193-286.

Dégremont, L. 2011. Evidence of herpesvirus (OsHV-1) resistance in juvenile Crassostrea gigas selected for high resistance to the summer mortality phenomenon. Aquaculture, 317: 94-98.

Diter, A., and Dufy, C., 1990. Polyploidy in the Manila clam, Ruditapes philippinarum, II. Chemical induction of tetraploid embryos. Aquat. Living Resour. 3: 107-112.

Downing, S.L., and Allen Jr;,S.K. 1987. Induced triploidy in the Pacific oyster Crassostrea gigas: optimal treatments with cytochalasin B depend on temperature. Aquaculture, 61: $1-15$.

Eudeline, B., Allen, S.K., and Guo, X. 2000. Optimization of tetraploid induction in Pacific oysters, Crassostrea gigas, using first polar body as a natural indicator. Aquaculture, 187: 73-84.

Gallardo, M.H., Bickham, J.W., Honeycutt, R.L., Ojeda, R.A., and Köhler, N. 1999. Discovery of tetraploidy in a mammal. Nature, 401: 341.

Gérard, A., Ledu, C., Phelipot, R., and Naciri-Graven, Y. 1999. The induction of MI and MII triploids in the Pacific oyster Crassostrea gigas with 6-DMAP or CB. Aquaculture, 174: 229-242.

Gérard, A., Naciri, Y., Peignon, J.M., Ledu, C., and Phelipot, P. 1994. Optimization of triploid induction by the use of 6-DMAP for the oyster Crassostrea gigas (Thuneberg). Aquaculture and Fisheries Management, 25: 709-719.

Gong, N., Yang, H., Zhang, G., Landau, B. J., and Guo, X. 2004. Chromosome inheritance in triploid Pacific oyster Crassostrea gigas Thunberg. Heredity, 93 (5): 408-415. 
Guo, X. 1991. Studies on tetraploid induction in the Pacific oyster, Crassostrea gigas (Thuneberg). Ph.D. Dissertation, University of Washington, Seattle, WA.

Guo, X., and Allen, S.K. Jr. 1994. Viable tetraploids in the Pacific oyster (Crassostrea gigas Thuneberg) produced by inhibiting polar body 1 in eggs from triploids. Mol. Mar. Biol. Biotechnol. 3(1): 42-50.

Guo, X., Cooper, K., Hershberger, W.K., and Chew, K.K. 1992. Genetic consequences of blocking polar body I with cytochalasin B in fertilized eggs of the Pacific oyster, Crassostrea gigas: I. Ploidy of resultant embryos. Biol. Bull. 183: 381-386.

Guo, X., DeBrosse, G.A., and Allen Jr., S.K. 1996. All-triploid Pacific oysters (Crassostrea gigas Thunberg) produced by mating tetraploids and diploids. Aquaculture, 142: 149161.

Guo, X., Hershberger, W.K., Cooper, K., and Chew, K.K. 1993. Artificial gynogenesis with ultraviolet light-irradiated sperm in the Pacific oyster, Crassostrea gigas. I. Induction and survival. Aquaculture, 113:201-214.

Guo, X., Wang, Y., Xu, Z., and Yang, H. 2009. Chromosome set manipulation in shellfish. In New Technologies in Aquaculture: Improving Production Efficiency, Quality and Environmental Management. Edited by G. Burnell and G. Allan. Woodhead Publishing in Food Science, Technology and Nutrition. pp. 165-194.

Hand, R.E., Nell, J.A., Reid, D.D., Smith, I.R., and Maguire, G.B. 1999. Studies on triploid oysters in Australia: effect of initial size on growth of diploid and triploid Sydney rock oysters, Saccostrea commercialis (Iredale and Roughley). Aquacult. Res. 30: 35-42.

Hegarty, M., and Hiscock, S. 2007. Polyploidy: doubling up for evolutionary success. Curr. Biol. 17: 927-929.

King, N., Janke, A., Roberts, R. and Kaspar, H. 2004. New Zealand oyster breeding program seeks genetic improvement. Global Aquaculture Advocate, 7: 59-61.

Langdon, C., Evans, F., Jacobson, D., and Blouin, M. 2003. Yields of cultured Pacific oysters, Crassostrea gigas Thunberg improved after one generation of selection. Aquaculture, 220: $227-244$

Mable, B.K. 2004. Why polyploidy is rarer in animals than in plants: myths and mechanisms. Biol. J. Linn. Soc. 82: 453-466.

Matt, J.L., and Allen, S.K. 2014. Heteroploid mosaic tetraploids of Crassostrea virginica produce normal triploid larvae and juveniles as revealed by flow cytometry. Aquaculture, 432: 336-345.

McCombie, H., Ledu, C., Phelipot, P., Lapegue, S., Boudry, P., and Gerard, A. 2005a. A complementary method for production of tetraploid Crassostrea gigas using crosses between diploids and tetraploids with cytochalasin B treatments. Mar. Biotechnol. 7: 318-330.

McCombie, H., Lapègue, S., Cornette, F., Ledu, C., Boudry, P. 2005b. Chromosome loss in bi-parental progenies of tetraploid Pacific oyster, Crassostrea gigas. Aquaculture, 247: 97-105.

Nell, J.A., Smith, I.R., and McPhee, C.C. 2000. The Sydney rock oyster Saccostrea glomerata (Gould 1850) breeding programme: progress and goals. Aquacult. Res. 31: 45-49.

Piferrer, F., Beaumont, A., Falguière, J.C., Flajshans, M., Haffray, P., and Colombo, L. 2009. Polyploid fish and shellfish: production, biology and applications to aquaculture for performance improvement and genetic containment. Aquaculture, 293: 125-156

Que, H., Guo, X., Zhang F,. and Allen, S.K. Jr. 1997. Chromosome segregation in fertilized eggs from triploid Pacific oysters, Crassostrea gigas (Thunberg) following inhibition of polar body 1. Biol. Bull. 193: 14-19. 
Rasmussen, R.S. and Morrissey, M.T. 2007. Biotechnology in aquaculture: transgenics and polyploidy. Comprehensive Reviews in Food Science and Food Safety, 6: 2-16. doi: 10.1111/j.1541-4337.2007.00013.x

Sheridan, A.K. 1997. Genetic improvement of oyster production: a critique. Aquaculture, 153: 165-179.

Stebbins, G.L. 1971. Chromosomal evolution in higher plants. Addison-Wesley Publishing Company, Mass., U.S.A.

Stephens, L.B. 1989. Inhibition of the first polar body formation in Crassostrea gigas produces tetraploids,. M.S. Thesis, University of Washington, Seattle, WA.

Stephens, L.B., and Downing, S.L. 1988. Inhibition of the first polar body formation in Crassostrea gigas produced tetraploids, not meiotic I triploids. J. Shellfish Res. 7 (3): 550-551 (Abstract).

Ward, R.D., English, L.J., Mcgoldrick, D.J., Maguire, G.B., Nell, J.A., and Thompson, P.A. 2000. Genetic improvement of the Pacific oyster (Crassostrea gigas Thunberg) in Australia. Aquacult. Res. 31: 35-44.

Yamamoto, S., Sugawara, Y., Nomaru, T., and Oshino, A. (1988). Induced triploidy in the Pacific oyster, Crassostrea gigas, and performance of triploid larvae. Tohoku J. Agr. Res. 39 (1): 47-59.

Yang, H., Zhang, F., and Guo, X. 2000. Triploid and tetraploid Zhikong scallop, Chlamys farreri Joene \& Preston, produced by inhibiting polar body I. Mar. Biotechnol. 2: 466475.

Yang, H., and Guo, X. 2004. Tetraploid induction by meiosis inhibition in the dwarf surfclam Mulinia lateralis (Say 1822): effects of cytochalasin B duration. Aquacult. Res. 35: 1187-1194.

Yang, H. and Guo, X. 2006. Polyploid induction by heat shock-induced meiosis and mitosis inhibition in the dwarf surfclam, Mulinia lateralis Say. Aquaculture, 252: 171-182.

Zhang, Q., Yu, H., Howe, A., Chandler, W. and Allen, S.K. Jr. 2010a. Cytogenetic mechanism for reversion of triploids to heteroploid mosaics in Crassostrea gigas (Thunberg) and Crassostrea ariakensis. Aquaculture Res. 41: 1658-1667.

Zhang, Q., Zhuang, Y., and Allen, S.K. Jr. 2010b. Meiotic chromosome configurations in triploid and heteroploid mosaic males of Crassostrea gigas and Crassostrea ariakensis. Aquaculture Res. 41: 1699-1706.

Zhang, Z., Wang, X., Zhang, Q., and Allen Jr., S. 2014a. Cytogenetic mechanism for the aneuploidy and mosaicism found in tetraploid pacific oyster Crassostrea gigas (Thunberg) J. Ocean Univ. China (Oceanic and Coastal Sea Research). 13 (1): 125-131.

Zhang, Z., Wang, X., Zhang, Q., and Allen, S.Jr. 2014b. Preferential bivalent formation in tetraploid male of pacific oyster Crassostrea gigas (Thunberg). J. Ocean Univ. China (Oceanic and Coastal Sea Research). 13 (2): 297-302.

Zouros, E., Thiriot-Quievreux, C., and Kotoulas, G. 1996. The negative correlation between somatic aneuploidy and growth in the oyster Crassostrea gigas and implications for the effects of induced polyploidization. Genetical Res. 68: 109-116. 
Table 1.

\begin{tabular}{cccccc}
\hline 2006 & $\begin{array}{c}\text { Eggs } \\
\text { (million) }\end{array}$ & $\begin{array}{c}\text { \% } \\
\text { Fertilization }\end{array}$ & $\begin{array}{c}\text { \% Survival } \\
\text { (day 1) }\end{array}$ & $\begin{array}{c}\text { \% tetraploid } \\
\text { larvae (day 1) }\end{array}$ & $\begin{array}{c}\text { Day of first } \\
\text { settlement }\end{array}$ \\
\hline (DT+PB2)-1 & 15 & 90 & 4 & 80 & 18 \\
(DT+PB2)-2 & 15 & 92 & 6 & 75 & 18 \\
(DD+PB1)-1 & 15 & 92 & 16 & 45 & 20 \\
(DD+PB1)-2 & 15 & 94 & 20 & 40 & 20 \\
(DD) & 15 & 95 & 65 & 0 & 18 \\
\hline
\end{tabular}

\begin{tabular}{cccccc}
\hline $\mathbf{2 0 1 2}$ & $\begin{array}{c}\text { Eggs } \\
\text { (million) }\end{array}$ & $\begin{array}{c}\text { \% } \\
\text { Fertilization }\end{array}$ & $\begin{array}{c}\text { \% Survival } \\
\text { (day 1) }\end{array}$ & $\begin{array}{c}\text { \% tetraploid } \\
\text { larvae (day 1) }\end{array}$ & $\begin{array}{c}\text { Day of first } \\
\text { settlement }\end{array}$ \\
\hline (TrD+PB1)-1 & 10 & 85 & 30 & 60 & 16 \\
(TrD+PB1)-2 & 10 & 90 & 40 & 45 & 16 \\
(DD+PB1)-1 & 15 & 95 & 20 & 25 & 20 \\
(DD+PB1)-2 & 15 & 90 & 26 & 35 & 20 \\
\hline
\end{tabular}

Table 2.

\begin{tabular}{l|c|c|}
\hline 2006 & Tetraploid & Heteroploid mosaic \\
\hline TrD+PB1 & 55 & 45 \\
DT+PB2 & 75 & 25 \\
DD+PB1 & 93 & 7 \\
\hline
\end{tabular}

\begin{tabular}{|l|c|c|}
\hline 2012 & Tetraploid & Heteroploid mosaic \\
\hline TrD+PB1 & 50 & 50 \\
DD+PB1 & 95 & 5 \\
\hline
\end{tabular}


Figure 1:
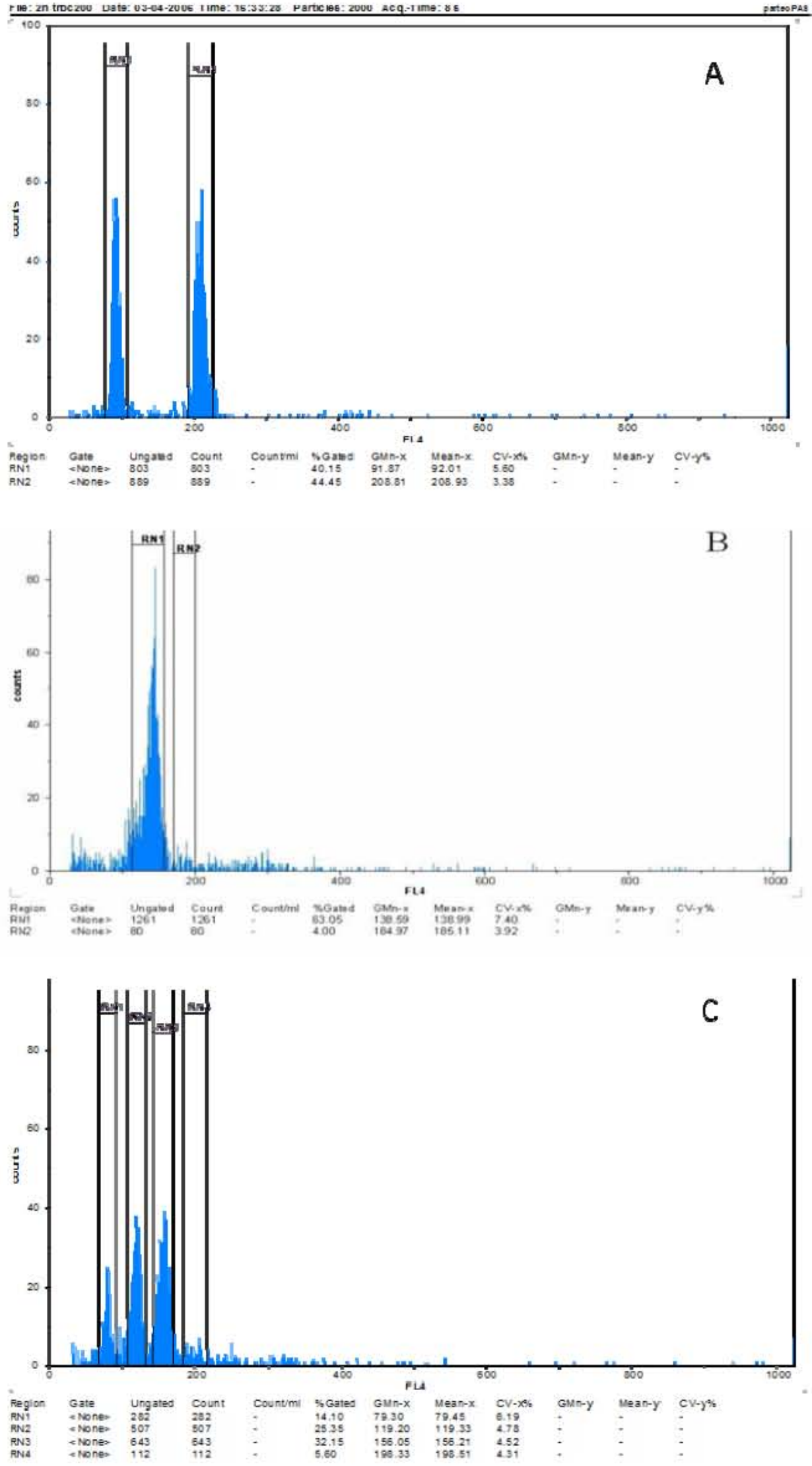
Figure 2:
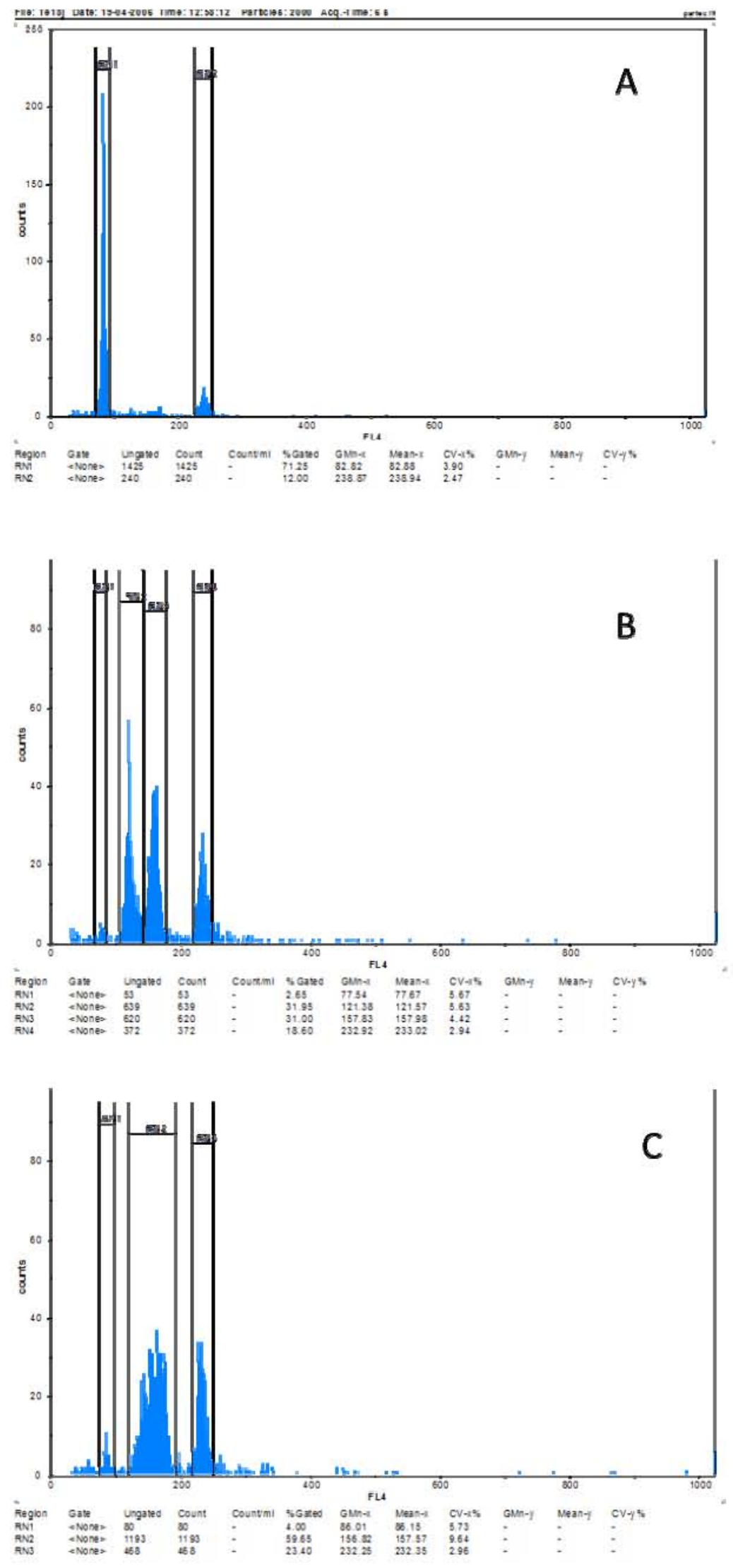
Figure 3:
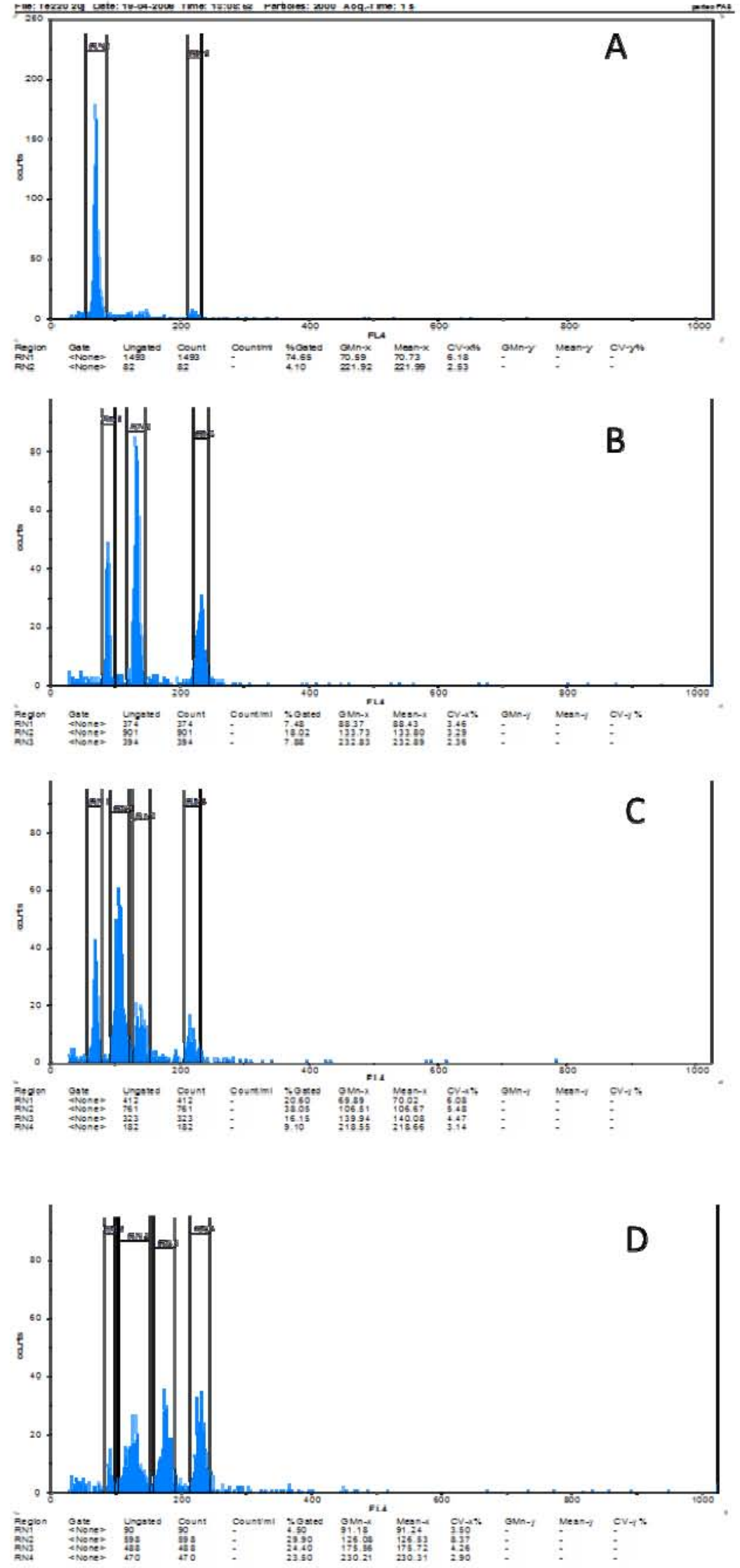
Figure 4:

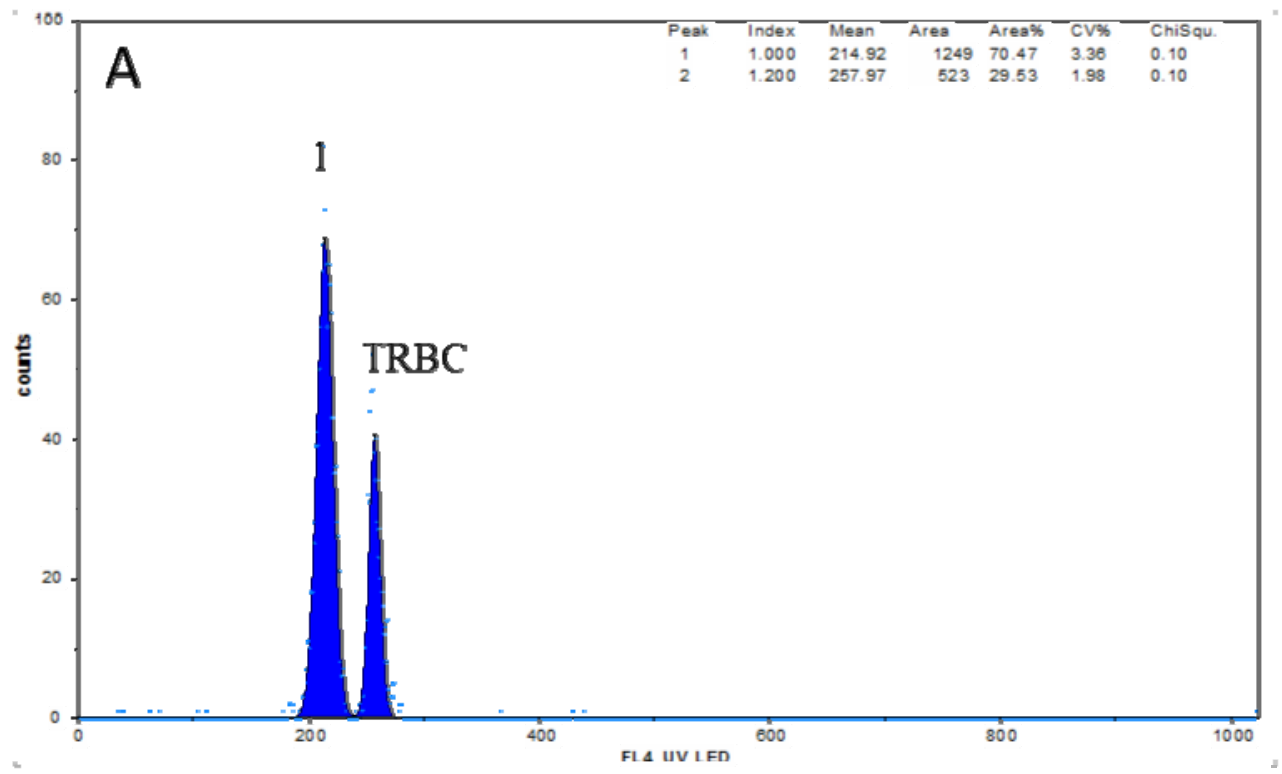

Figure 5:

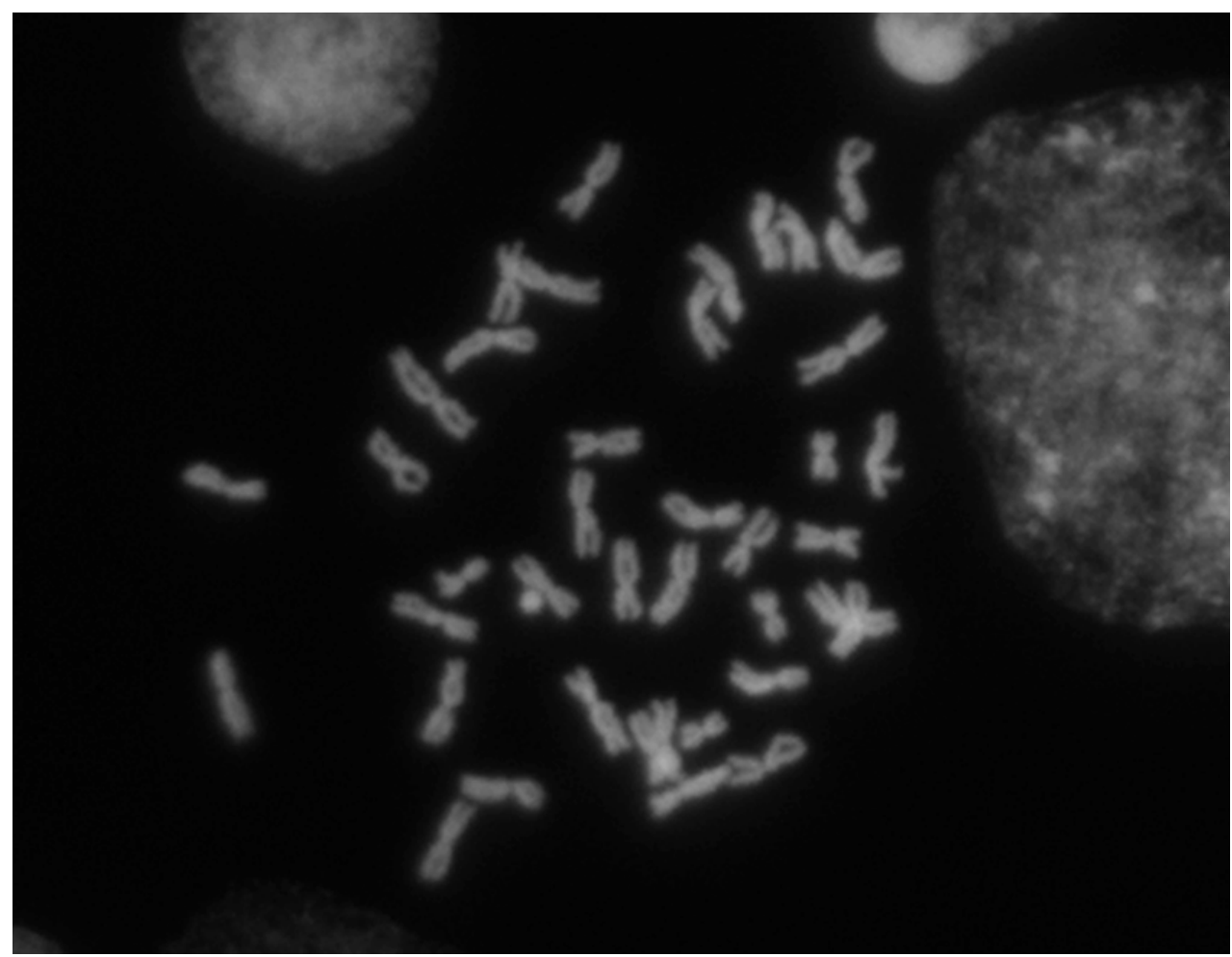


Figure 6:
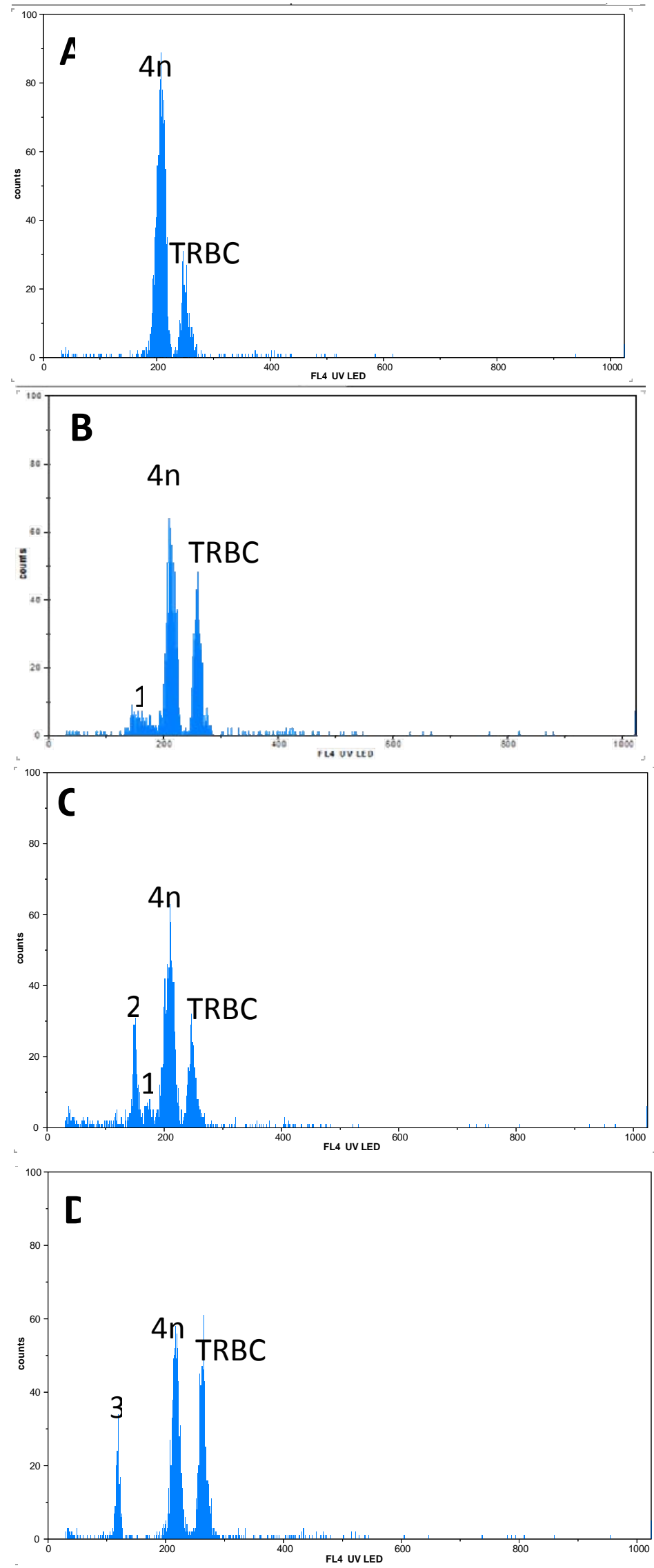
Figure 7:
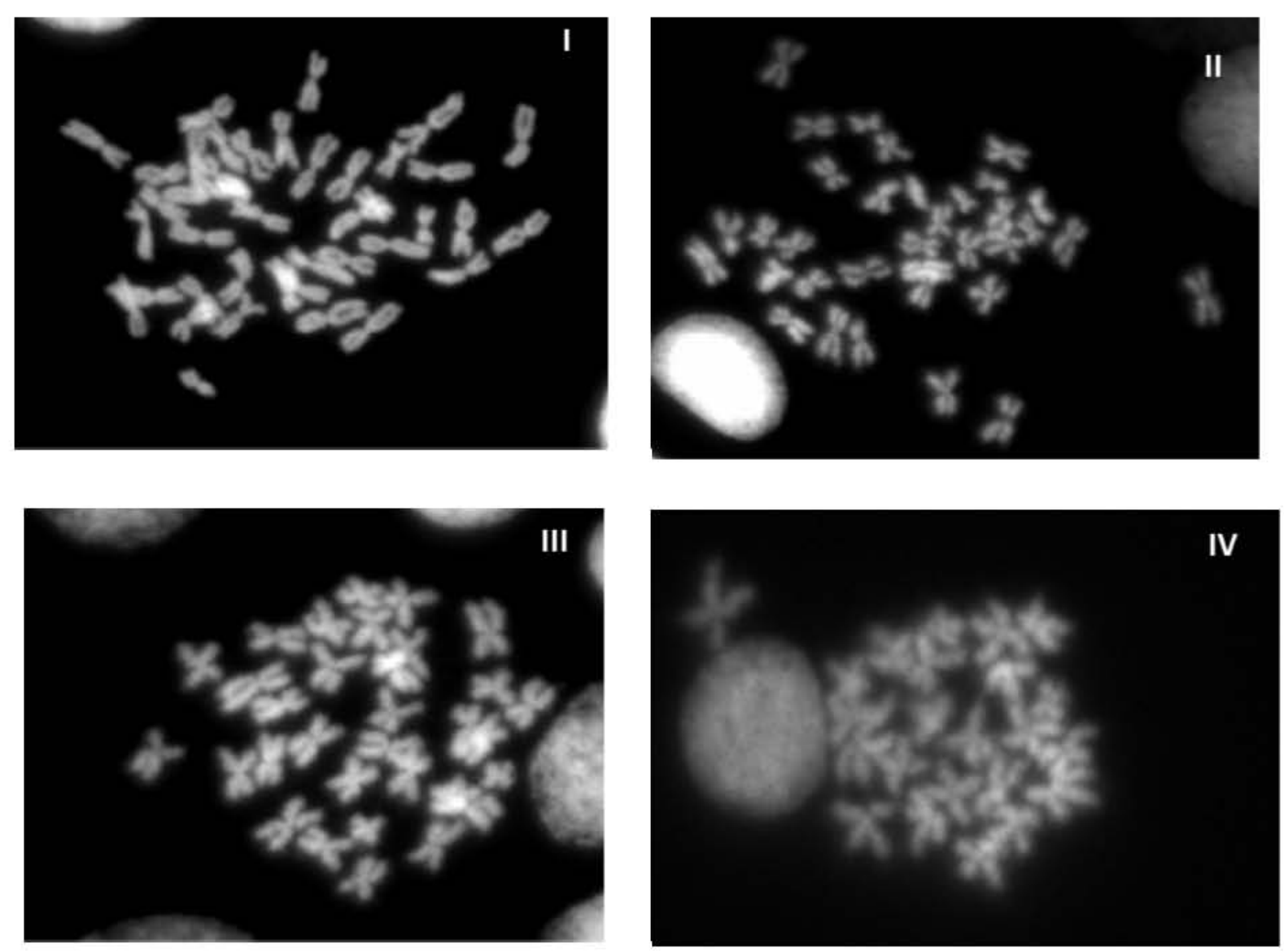
Table 1: 2006 and 2012 inductions: Number of eggs fertilized, percent of fertilization, survival of D-stage larvae, percent of induced tetraploid larvae and first day of settlement. Starting from day 4, larvae were cultured in duplicate in $150 \mathrm{l}$ fiber glass tanks at maximum density of 10 larvae per ml.

Table 2: Percentage of tetraploids and mosaics after two years of rearing starting from two pure tetraploid oysters populations established in 2006 and 2012.

Figure 1: FCM analysis of 1-day old larvae. (A) In control batch, larvae were in the diploid range (RN1). (B) "Indirect method" (DT+PB2): $80 \%$ of the detected nuclei were in a continuous triploid-tetraploid peak (RN1). (C) "Direct method"(DD+PB1): tree nuclei populations were detected in the range of diploid (17\%, RN1), triploid (38\%, RN2) and tetraploid (45\%, RN3) ploidy levels, respectively. The internal standard TRBC is represented by the last peak in each analysis (RN2 in A and B, and RN4 in C).

Figure 2: FCM histograms of 18-day old larvae resulting from "indirect method"(DT+PB2). (A) Control batch: pediveliger larvae were in the diploid range (RN1). (B) pediveliger larvae from the treated group were in the range of tetraploid (48\%, RN3), triploid (47\%, RN2) and diploid (5\%, RN1) ploidy levels. (C) Treated larvae from the smallest $(180-\mu m)$ size class. In this slow growing class, tetraploids were included in a large and continuous triploid/tetraploid peak (RN2) representing the majority of analyzed larvae. In each histogram, the last peak represented TRBC.

Figure 3: FCM analysis of 18-day old larvae from "direct method“(DD+PB1). (A) Control batch: pediveliger larvae were in the diploid range (RN1). (B) Pediveliger larvae from the treated group were in majority triploids (70\%, RN2) and diploids (30\%, RN1). (C) In large $(180-\mu \mathrm{m})$ size class larvae, tetraploids were detected in a small peak representing $20 \%$ of analyzed larvae (RN3). (D) In larvae from small $(150-\mu \mathrm{m})$ size class, tetraploids were more frequent and detected in peak representing $40 \%$ of analyzed larvae (RN3). In each histogram, the last peak represented TRBC.

Figure 4: nondestructive FCM analysis at 6 months PF. Peak 1, tetraploid nuclei. TRBC is the internal standard.

Figure 5: typical metaphase plate of a tetraploid oyster with 40 chromosomes.

Figure 6: (A) Flow-cytometric histogram of eutetraploid individual (4n), (B-D) Three different heteroploid mosaics showing in addition to tetraploid nuclei (4n) various populations of mainly aneuploid nuclei as discrete population of nuclei in intermediate euploidy levels. (1) hypertriploid to hypotetraploid nuclei. (2) hypo to hypertriploid nuclei and (3) hyperdiploid nuclei. TRBC is the internal standard.

Figure 7: Metaphase chromosomes from gill tissues of eutetraploid and heteroploid mosaics of C. gigas. Eutetraploid individuals showed only gill cells with 40 chromosomes (I). Mosaics showed in addition to eutetraploid cells variable proportion of cells with different chromosome constitution including 34 (II), 32 (III), and 23(IV) chromosomes. 